\title{
Intra Serotal lymphangioma Presenting as Hydrocele
}

\section{Abstract:}

Scrotal lymphangiomas are rare lesions caused by lymphatic malformations. They present as painless scrotal swelling and are easily misdiagnosed as hydrocele. We report a case of 8 year old child who presented with scrotal swelling which was identified sonographically and pathologically as lymphangioma and managed by surgical excision. Preoperative recognition of this clinical entity by ultrasound is essential for planning of appropriate treatment.

Key words: Lymphangioma, Scrotum, Hydrocele, Lymphatic malformation.

\section{Introduction}

Lymphangiomas are benign, non-encapsulated lesions caused by congenital malformations of the lymphatic system. Lymphangiomas are commonly seen in the neck (75\%), axilla (20\%). Other lesser common sites include mediastinum, retroperitoneum, bone, liver, kidney and scrotum [1]. Scrotum and perineum are the least common sites [2]. Lymphangiomas are the result of the failure of lymphatic drainage from sequestrated lymphatic channels with consequent dilatation of the ducts and formation of multi-septate cystic masses. Clinical presentation includes painless cystic scrotal swelling. Scrotal Lymphangiomas are frequently misdiagnosed on clinical examination as hydrocele, varicocoele, haematocele, inguinal hernia. We here present a case of scrotal lymphangioma in a pediatric patient who presented to us with hydrocele.

\section{Case Report}

A 8 year old child presented to the pediatric surgical outdoor clinic with a painless right scrotal swelling. There was no past history of trauma, infection or positive family history. Local examination revealed $3 \times 4 \mathrm{~cm}$, soft, slightly compressible, irreducible right scrotal swelling located superior to testicle. Examination of bilateral testis, skin over the swelling, inguinal lymph nodes, neck and axilla did not reveal any abnormality. Ultrasonography (USG) of the right scrotum revealed the presence of cystic mass with multiple septae of varying size without any evidence of calcification or testicle abnormality. USG of the left scrotal sac and abdomen was normal. Based on clinical and radiological findings, differential diagnosis of lymphangiomas, complex hydrocele or spermatocele were considered.

Exploration revealed multiple cysts of varying sizes filled with clear serous fluid [Fig. 1]. Vas deferens along 
with vessels was dissected free from the large hernia sac [Fig. 2]. Sac was transfixed and excised. The swelling was excised completely including the tunica vaginalis. Histopathogical examination showed numerous collapsed, irregular, cavernous spaces with attenuated endothelial cells. Intervening stroma had loose connective tissue with small blood vessels. Lymphocyte infiltration was seen around these small blood vessels [Fig. 3]. No atypia or hyperchromatic activity was seen in the endothelial lining. The pathological diagnosis was compatible with scrotal lymphangioma.

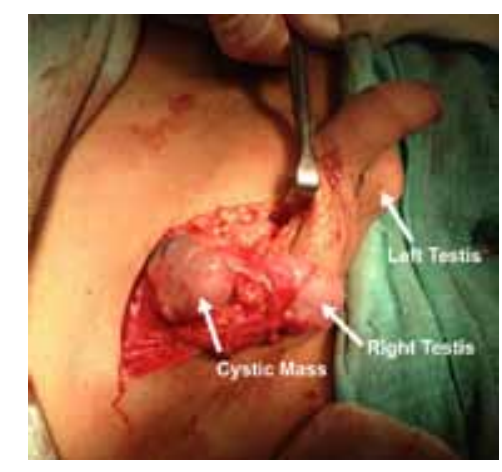

Fig.1: Lymphangioma dissected from scrotum

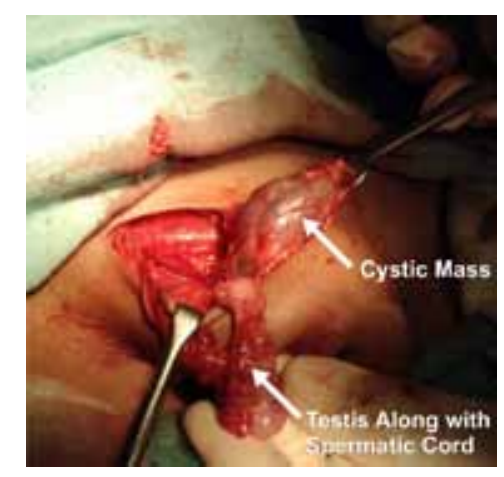

Fig.2: Lymphangioma separated from testis and cord

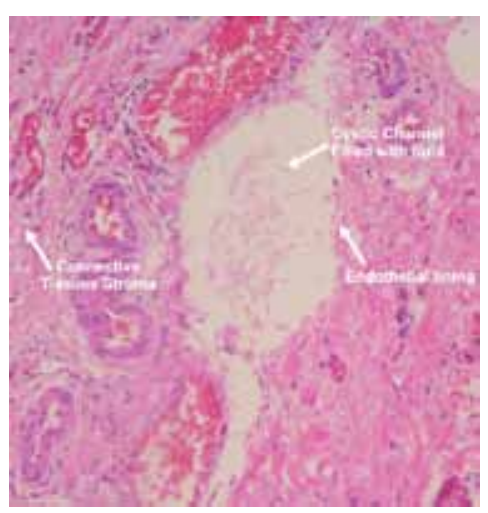

Fig.3: Cystic lymphatic channel with endothelial lining 


\section{Discussion}

Scrotal lymphangiomas are congenital lymphatic malformations generally congenital in origin but can also be acquired secondary to infection, inflammation or trauma [2]. 50\% of the scrotal lymphangiomas present at birth [3] and $90 \%$ of them are clinically evident by 2 years of age. Different nomenclatures used for lymphangiomas are cystic hygroma, congenital lymphatic hamartoma, cystic lymphangiomas. Lymphangiomas most commonly occurs in the neck or axilla and remaining $5 \%$ are seen in mediastinum, retroperitoneum, mesentery, bone and thighs $[4,5,6,7]$. Scrotum and perineal region are the least common sites. These lesions are commonly seen in children and have no sex predilection. Clinical presentation includes slow growing, benign, painless, extratesticular scrotal swelling [4]. They are commonly misdiagnosed as a hernia, hydrocele, varicocele which may result in incomplete therapy with a risk of recurrence.

Whimster in 1976, first described the pathophysiology of lymphangiomas [8]. He concluded that lymphangiomas result from failure of primitive lymphatic cisterns in the deep subcutaneous plane to connect with rest of lymphatic system during fetal life. Lymphangiomas are divided into cystic lymphangiomas, cavernous lymphangiomas and capillary lymphangiomas [9]. The differential diagnosis of intra-scrotal cystic lymphangioma include loculated hydrocoele, hematocole, varicocele and spermatocoele. The histopathologic features consists of increased number of dilated lymphatic vessels that are lined by endothelium. The cystic spaces are filled with serous lymphatic fluid. The connective tissue stroma has spindle-shaped smooth muscle cells, collagen and fibroblasts.

High resolution ultrasound is accurate in determining the type and extent of lesions. The USG findings of scrotal lymphangiomas are multi-cystic extratesticular scrotal mass filled with homogeneous echo free fluid. Presence of echoes implies infection or haemorrhage. Septations show low velocity and high resistance vascular flow [10]. Medical treatment includes injection of sclerosants, fulgration, laser or cryotherapy but is associated with high recurrence rates $[11,12]$. Complete surgical excision of lymphangiomas is the gold standard treatment modality [13-15]. Recurrence is common with incomplete excision.

\section{Conclusion}

Scrotal lymphangiomas are benign lesions which should be considered in the differential diagnosis of painless extra-testicular intra-scrotal mass. Treatment includes complete surgical excision with high recurrence rates associated with incomplete resection. Recognition of this clinical entity pre-operatively by sonography is essential for planning of appropriate treatment.

\section{References}

1. Mosca RC, Pereira GA, Mantesso A. Cystic Hygroma: characterization by computerized tomography. Oral Surg Oral Med Oral Pathol Oral Radiol Endod. 2008;105(5):e 65-69.

2. Hamada Y, Yagi K, Tanano A Kato Y, Takada K, Sato M, Hioki K. Cystic Lymphangioma of the scrotum. Pediatr Surg Int. 1998; 13:442-444.

3. Roger EM, Bruce RM, Harlan DA. Scrotal Lymphangioma. Urology 1984;23:79-80. 
4. Richard SH, Ellen S, William C, David AD, Anthony JC, Richard CR. Scrotal cystic Lymphangioma: The misdiagnosis scrotal mass. J Urol. 1997;158:1182-1185.

5. Takahiro Y, Hidentoshi A, Katsumasa K, Kenjiro K. Scrotal Lymphangioma. Urol Int. 1998;61:178-180.

6. Stanisklav TM, Kaje SB, Frederick WW. Cystic Lymphangioma of the scrotum. J Urol. 1984;131:11791181.

7. Thomas LJ, Gorm S, Annete E. Lymphangioma of the scrotum. Scand J Urol Nephrol. 1999;33:205-206.

8. Whimster IW. The pathology of Lymphangioma circumscriptum. Br J Dermatol. 1976;94:473-486.

9. Mulcahy J J, Schileru G, Donmezer MA, Bhathema D. Lymphangioma of scrotum. Urology 1979; 14:6465.

10. Loberant N, Chernihovski A, Goldfeld M et al. Role of Doppler sonography in the diagnosis of cystic lymphangioma of the scrotum. J Clin Ultrasound. 2002;30:384-387.

11. Alqahtani A, Nguyen LT, Flageole H, Shaw k, Larberge JM. 25 years' experience with Lymphangiomas in children. J Pediatr Surg.1999;34:1164-1168.

12. Morani A K, Asrani A, Maheshwari P. Cystic Lymphangioma of the scrotum. Applied Radiology online AR online(Case Reports)2006;35(4).

13. Hurwitz RS, Shapiro E, Hulbert WC, Diamond DA, Casale AJ, Rink RC. Scrotal cystic Lymphangioma: the misdiagnosed scrotal mass. J Urol. 1997;158:1 182-1185.

14. Grossgold E T, Kusuda L. Scrotal Lymphangioma in an adult. Urology. 2007;70(3):590.

15. Lin E, Yang S. Cystic Lymphangioma in the pelvic cavity. JTUA 2003; 14:92-94. 